\title{
SALUD MENTAL, GÉNERO Y ENSEÑANZA REMOTA DURANTE EL CONFINAMIENTO POR EL COVID-19 EN MÉXICO
}

\author{
Alicia Saldívar-Garduño \\ https://orcid.org/0000-0002-6863-0944 \\ Karol Esthefanya RamíREZ-Gómez \\ Universidad Autónoma Metropolitana, Iztapalapa, México \\ Correo electrónico: asaldivarg@gmail.com
}

Recibido: 28 de septiembre del 2020 / Aceptado: 21 de octubre del 2020

doi: https://doi.org/10.26439/persona2020.n023(2).5011

\begin{abstract}
Resumen. Debido a la pandemia del COVID-19, causada por la aparición del nuevo virus SARS-CoV-2 en el mundo, y su posterior llegada a México, el 23 de marzo el Gobierno Federal y el Consejo Nacional de Salubridad declararon el inicio de la Jornada Nacional de Sana Distancia para prevenir la diseminación masiva del virus, la cual incluía la suspensión de las clases en todos los niveles. Ante esta situación, las comunidades escolares tuvieron que enfrentarse a un escenario incierto e inédito, teniendo que continuar las labores educativas de manera repentina por vía remota. Esto ha traído consigo modificaciones en los hábitos y las rutinas, así como alteraciones de la salud mental del personal académico y de estudiantes, quienes han resentido esta situación experimentando estrés, cansancio y frustración, debido a la excesiva carga de trabajo, a la falta de habilidades tecnológicas y a carencias en la adaptación a la nueva normalidad. Asimismo, se ha dejado entrever claramente la desigualdad de género, que afecta de manera importante a las mujeres, debido a los múltiples roles que deben cumplir durante la cuarentena, como madres, estudiantes, cuidadoras del hogar y de personas enfermas.
\end{abstract}

Palabras clave: salud mental / género / enseñanza remota / contingencia / COVID-19

\section{MENTAL HEALTH, GENDER AND REMOTE TEACHING DURING COVID-19 LOCKDOWN IN MEXICO}

Abstract. Due to the COVID-19 pandemic caused by the emergence of a novel virus called SARS-CoV-2 in the world, and its subsequent arrival in Mexico, the Federal 
Government and the National Health Council declared on March 23 the start of the National Season of Healthy Distance to prevent the mass spread of the virus, which included the suspension of in-person classes at all levels. In this situation, school communities faced an uncertain and unknown scenario, and suddenly had to continue the educational work in a remote way. This scenario has led to changes in habits and routines, and has affected the mental health of both academic staff and students, who experience stress, tiredness and frustration due to the excessive workload, lack of technological skills, and gaps in adapting to "the new normal." Gender inequality, which significantly affects women, has also been clearly seen because of the multiple roles they must play during quarantine as mothers, students, family caregivers and providers of care for sick family members.

Keywords: mental health / gender / remote teaching / contingency / COVID-19 


\section{INTRODUCCIÓN: LA PANDEMIA POR EL COVID-19 EN MÉXICO}

Como ya es de dominio público, el 31 de diciembre del año 2019, en la ciudad de Wuhan, China, se identificó un nuevo virus, de la familia de los coronavirus, el cual comenzó a diseminarse rápidamente en esa ciudad provocando las primeras muertes. Aun cuando el gobierno chino trató de contener los contagios confinando a su población y limitando la movilidad fuera de la ciudad, el virus se dispersó por todo el país y, después, a otras naciones asiáticas hasta llegar a Europa; a principios de este año, llegó a Estados Unidos, así como a otros países en el continente americano. Debido a este comportamiento del virus y de la epidemia, la Organización Mundial de la Salud (OMS, 2020) emitió una declaratoria de emergencia de salud pública de interés internacional en enero del 2020, y en marzo la catalogó como pandemia.

En México, el 27 de febrero del 2020 fue identificado el primer caso importado de coronavirus en un varón adulto que había viajado a Italia ("Coronavirus en México: confirman los primeros casos de covid-19 en el país", 2020); a partir de ese momento, la epidemia avanzó, primero de manera lenta, pero después creció en forma exponencial. El 23 de marzo, el Gobierno Federal y el Consejo Nacional de Salubridad establecieron la Jornada Nacional de Sana Distancia (Gobierno de México, 2020) para evitar la diseminación masiva, después de reconocer al coronavirus como una enfermedad grave de atención prioritaria. Con esta medida, se decretó la suspensión temporal de actividades catalogadas como no esenciales en el ámbito público, social y privado, durante un período que en principio se estimó en cuatro semanas, pero que se extendió por varios meses. Es decir que las personas que no realizaban actividades esenciales debían resguardarse en sus domicilios de manera preventiva y relativamente obligatoria (a diferencia de otros países, no se establecieron sanciones oficiales para quienes no respetaran la medida), y solo podrían salir para adquirir alimentos, artículos de limpieza y medicamentos. En esa fecha también se suspendieron las clases presenciales en todos los niveles escolares.

Durante el primer mes de la Jornada Nacional de Sana Distancia, las autoridades sanitarias reportaron una reducción de la movilidad del $67 \%$ en promedio, y esta alcanzó hasta $82 \%$ en algunas alcaldías de la Ciudad de México, con variaciones por tipo de actividad ("La contingencia redujo la movilidad en $67 \%$ a nivel nacional, según el gobierno", 2020):

- $66 \%$ en compras y espacios de entretenimiento

- $63 \%$ en estaciones de transporte

- $50 \%$ en lugares de trabajo

- $20 \%$ en residencias (reuniones) 
Desde el principio de la pandemia, la mayoría de los casos de coronavirus se concentraron en la Ciudad de México por su densidad poblacional, y la alta movilidad nacional e internacional que la caracterizan. Además, gran parte de las personas infectadas en el país pertenecen al rango de edad de entre 30 y 59 años, y hay una mayor incidencia en la población masculina; las principales comorbilidades reportadas en las personas fallecidas son hipertensión, obesidad y diabetes (Suárez, Suárez Quezada, Oros Ruiz y Ronquillo de Jesús, 2020). El 1 de junio inició la reapertura social y económica gradual, regulada con un semáforo por regiones, lo que ha provocado que en muchos lugares las personas hayan abandonado ya el confinamiento. Al 22 de septiembre, la cantidad de contagios a nivel nacional fue de 705263 personas, con 74348 fallecimientos, lo cual muestra que, a pesar de los esfuerzos, el número de contagios sigue siendo muy alto (Secretaría de Salud, 2020).

\section{Cambio de hábitos}

La situación de confinamiento ha producido modificaciones importantes en los hábitos y en las rutinas de las personas alrededor del mundo. En primer lugar, la convivencia familiar pasó de ocurrir durante unas horas cada día a ser de tiempo completo a partir de la declaración de la emergencia sanitaria. Por otra parte, los espacios familiares se adaptaron para darles un uso escolar y laboral, pues el trabajo presencial se suspendió y comenzó la modalidad de trabajo a distancia o "teletrabajo", de la misma manera que las clases presenciales en todos los niveles se suspendieron y dieron paso a las clases remotas o virtuales. Con todo esto, la realidad previa a la pandemia se transformó en una nueva normalidad.

\section{Convivencia familiar}

El trato de tiempo completo con la familia puede ser agobiante, pero también representa una oportunidad para reducir el ritmo de vida frenético en el que las personas estábamos sumergidas antes de la pandemia. Esa situación ha traído consigo el reto de gestionar la crianza, la educación remota, el trabajo a distancia, los quehaceres domésticos y, en algunos hogares, también el cuidado de personas mayores o con discapacidad, principalmente a cargo de las mujeres. En opinión de Martínez (como se citó en Millet, 2020), estas dificultades deberían permitir que los miembros de la familia medien y negocien las emociones propias y las de los demás, así como otros estados como el aburrimiento, los gritos, las peleas y los conflictos que surjan ante esta situación inédita. Entre otras cuestiones, el autocontrol de las personas adultas se pone a prueba, y se genera la sensación de que deben solucionar todo, así se trate de enojos entre hermanas o hermanos, o cualquier otra eventualidad (Sanchís, 2020), lo que provoca estrés y desgaste. Un estudio realizado en los días posteriores al confinamiento por la contingencia sanitaria por el virus H1N1 en la Ciudad de México en abril del año 2009 mostró 
que la convivencia forzada a la que se vio sometida la población contribuyó a reforzar las dinámicas familiares previas, y propició la aparición de tensiones y conflictos entre sus integrantes; además, ese evento evidenció los recursos con los que las familias contaban para manejar esa situación excepcional, así como una mayor o menor flexibilidad para ajustarse a los cambios, con variaciones obvias (Estrada Iguíniz, 2010).

\section{Del trabajo presencial al "teletrabajo"}

Como ya se ha mencionado, en el momento en que se declaró la Jornada Nacional de Sana Distancia, el 23 de marzo, se suspendieron todas las actividades no esenciales y millones de personas en el país dejaron de asistir a sus espacios de trabajo, para realizar sus actividades desde sus hogares. El home office o teletrabajo es una modalidad que ya existía en México antes de la pandemia, pero que con la crisis sanitaria se posicionó como una alternativa que permitió que un número importante de empresas pudieran continuar con sus labores y, al mismo tiempo, proteger a sus trabajadoras y trabajadores del contagio por coronavirus (Hernández y Juárez, 2020), porque ofrece una mayor flexibilidad y accesibilidad.

El teletrabajo ha mostrado tener otras ventajas, tales como un aumento en la productividad, un mejoramiento en la calidad de vida de los empleados y empleadas, una mayor eficiencia en los procesos de las empresas, y una contribución positiva al medio ambiente. Según datos de la agencia DW/Serban (como se citó en Sánchez, 2020), un estudio mostró que el $40 \%$ de los trabajadores consideraba el teletrabajo como un equilibrio entre la vida personal y laboral, que había incrementado en 30 \% la productividad individual de los colaboradores y en $10 \%$ la colaborativa; por otro lado, al no invertir tiempo en el traslado del hogar al sitio de trabajo, se libera tiempo de vida personal'.

Antes de la pandemia, alrededor del $5 \%$ de la población trabajadora en América Latina ya había adoptado el teletrabajo, y ese porcentaje aumentó de manera significativa con el confinamiento. Su aplicación dependerá, sin embargo, de factores tales como la complejidad del negocio, la cantidad de empleados que tiene una empresa y el estado en que esta se encuentra respecto de la tecnología digital (DW/Serban, como se citó en Sánchez, 2020); a lo anterior hay que agregar el uso de las herramientas tecnológicas, el entrenamiento que se tenga y el hecho de contar con los recursos adecuados.

La empresa Citrix publicó los resultados de una encuesta (como se citó en F. Hernández, 2020), en la que el $77 \%$ de las personas que participaron admitieron que sus empresas tuvieron problemas para implementar el teletrabajo en poco tiempo,

1 Sánchez (2020) cita datos de la Encuesta de Origen Destino en Hogares de la Zona Metropolitana del Valle de México, que indicaban que, en el año 2017, el 58,1 \% de las personas tardaban entre 31 minutos y 2 horas en llegar a su trabajo. 
debido a la contingencia, pero también que el $56 \%$ pensaba que ahora su horario es más flexible, y el $49 \%$, que esa modalidad aumenta la productividad, les permite tener tiempo para descansar, hacer ejercicio u otras actividades. El 59 \% consideró que sus empresas tendrán después de la pandemia una cultura más digital, y el $44 \%$, que esta experiencia ayudará para que los líderes de sus organizaciones tengan más confianza en sus colaboradores, y que mejorará la cultura de sus compañías.

Aunque el teletrabajo tiene muchas ventajas, también presenta situaciones indeseables. Una encuesta reportada por la revista Forbes (Hernández Armenta, 2020) reveló que si bien al principio la idea del home office entusiasmó a muchas personas, también ocurrió que, transcurridas unas semanas, comenzaron a surgir las siguientes inquietudes (Hernández Armenta, 2020):

- El $60 \%$ de los latinoamericanos considera que en la oficina se tienen más posibilidades de hablar de proyectos u objetivos en grupo y generar más ideas.

- $\quad$ El $23 \%$ dice extrañar a sus compañeros de oficina.

- El $33 \%$ dice que el principal problema que observa es trabajar fuera del horario habitual y más horas que antes.

- Al $16 \%$ le cuesta desconectarse y poner límites entre su vida personal y profesional.

- A un $12 \%$ le falta equipamiento para trabajar de forma saludable.

- El $9 \%$ dice que no se toma los mismos descansos que estando en oficina.

- Un 8 \% siente que hay falta de comunicación en el equipo y eso le impide realizar bien su trabajo.

- El $6 \%$ señala no contar con apoyo constante de parte de su líder.

Como se puede inferir, a pesar de que la rápida implementación del teletrabajo permitió no detener las actividades productivas en nuestro país y en el mundo, para una proporción importante de personas, el efecto real fue que hubo un aumento en la carga laboral, una demanda de actividades a cualquier hora del día o de la noche, y un traslape con la vida familiar, especialmente por la ausencia de una normatividad clara para esa modalidad. Actualmente, existe un proyecto de reforma para regular el trabajo a distancia, que fue aprobado por la Cámara de Senadores en junio del 2019, el cual establece derechos y obligaciones para empleadores y colaboradores; desde septiembre de ese año, la minuta para modificar el artículo 311 de la Ley Federal del Trabajo se encuentra en la Cámara de Diputados, pero aún no ha sido aprobada. En el proyecto mencionado se define al teletrabajo o home office como las labores que se ejecutan para un patrón, para distinguirlo del empleo independiente o freelance, y se ordena que el convenio entre las partes debe considerar las condiciones del servicio, los medios 
tecnológicos y el ambiente requerido para llevar a cabo el trabajo, entre otros elementos (Hernández y Juárez, 2020; Juárez, 2019; Navarrete, 2020). Esto último incluye no atender temas laborales a cualquier hora, capacitación en la cultura del trabajo a distancia, y respeto al tiempo dedicado al ocio, el entretenimiento, la familia y el cuidado.

\section{DE LAS CLASES PRESENCIALES A LA EDUCACIÓN REMOTA O VIRTUAL}

Con la llegada de la pandemia, así como el trabajo presencial migró al teletrabajo o home office, la educación presencial también se vio obligada a trasladarse al espacio virtual. De acuerdo con los registros oficiales, en México hay alrededor de 36,6 millones de estudiantes de todos los niveles (3,9 millones cursan estudios superiores) y 2,1 millones de profesoras y profesores (Moreno, 2020).

La suspensión de las clases coincidió con el primer período vacacional escolar del año, y al menos durante dos semanas no hubo actividades académicas; una vez pasado ese lapso, la Secretaría de Educación Pública (SEP) determinó que se reanudaran las clases en forma remota. Esta decisión tomó por sorpresa a docentes y a estudiantes, quienes se vieron ante el reto de la educación virtual; pronto se pusieron en evidencia las carencias de un sistema que dependía demasiado de la modalidad presencial y del acceso a la tecnología (Escotto, 2020), pues el contacto entre las profesoras y los profesores y sus estudiantes se dio principalmente por internet. Así se concluyó el ciclo escolar 20192020 y, después de las vacaciones de verano, comenzó el 2020-2021, con el proyecto “Aprende en casa II", implementado por la SEP para educación básica y en el nivel medio. Las instituciones de educación superior, por su parte, gradualmente retomaron sus actividades, apoyadas principalmente en herramientas como las teleconferencias, las aulas virtuales, el correo electrónico y las redes sociales digitales como Facebook y WhatsApp, aun cuando la totalidad de sus comunidades estudiantiles no contaban con los medios para hacerlo, ni sus profesoras y profesores con los recursos y las habilidades para realizar labores de enseñanza remota, por las condiciones de conectividad que se viven en el país.

Según la Encuesta Nacional sobre Disponibilidad y Uso de Tecnologías de la Información en los Hogares (ENDUTIH), levantada en el año 2019 por el Instituto Nacional de Estadística y Geografía (INEGI), la Secretaría de Comunicaciones y Transportes (SCT), y el Instituto Federal de Telecomunicaciones (IFT), reveló que en ese momento había 80,6 millones de personas usuarias de internet, las cuales representaban el 70,1 \% de la población de 6 años o más. Las principales actividades relacionadas con el uso de internet que se reportaron fueron estas: entretenimiento (91,5\%), obtención de información $(90,7 \%)$ y comunicación $(90,6 \%)$; otro hallazgo fue que internet era utilizado principalmente por la población urbana $(76,6 \%)$, mientras que en las zonas rurales la población conectada era $47,7 \%$. Los tres principales medios para conectarse a internet 
fueron teléfono celular inteligente o smartphone (95,3\%), computadora portátil (33,2\%) y computadora de escritorio (28,9\%) (INEGI, SCT e IFT, 2020).

Una encuesta realizada por el Instituto Nacional de la Juventud (INJUVE, 2018) entre jóvenes entre 12 y 29 años arrojó los siguientes resultados en el área de la tecnología:

- Alrededor del 33 \% pasaba de 8 a 12 horas al día frente a una pantalla: celular, televisión, videojuegos, computadora o tableta.

- El 35 \% buscaba información sobre educación y formación.

- El 33 \% busca información para la escuela.

Estos datos muestran que no todos los hogares del país contaban con los recursos necesarios para enfrentar el reto de la educación virtual, y eso trajo consigo una serie de situaciones que han afectado de manera importante la salud mental de la población en nuestro país.

\section{Educación remota}

Por todo lo que ya se ha expuesto, se comprende que el confinamiento colocó a la población mexicana en una condición que complicaba la realización óptima de la educación remota, virtual o a distancia, por razones como las siguientes:

- Condiciones poco adecuadas en los espacios físicos. Los hogares no están diseñados para ofrecer o tomar clases a distancia, de modo que se han tenido que adaptar para colocar una mesa o un escritorio, o utilizar algún rincón de una sala, una recámara o el comedor familiar para ese fin.

- A diferencia de los salones de clases, en las casas particulares hay ruido, no se cuenta con la luz adecuada para trabajar, o bien hay un exceso de iluminación u otros distractores que dificultan la labor.

- Falta de recursos tecnológicos. No todas las familias cuentan con una computadora de escritorio, una laptop, una tableta o un teléfono celular, o bien tienen que compartir ese recurso con uno(a) o más hermanos(as).

- Una conectividad limitada o lenta. Los paquetes de internet contratados tenían fines domésticos, o para la realización de tareas escolares, pero no para ser utilizados a tiempo completo, ni para una carga de datos como la que se requiere, ya que, además de niñas y niños o adolescentes tomando clases, es muy probable que uno o los dos padres se encuentren realizando teletrabajo.

- Carga de trabajo excesiva. La educación remota se sumó al trabajo de los padres, a las tareas domésticas y a los cuidados de niñas, niños, personas adultas mayores o personas con discapacidad. Además, hay dificultad para poner límites entre los temas domésticos y los asuntos laborales. 
- Pasar demasiadas horas sentadas o sentados. Esto provoca cansancio, rigidez y contracturas.

- Molestias físicas, como resequedad en los ojos, a causa de la exposición excesiva a las pantallas.

- Tener un familiar enfermo en casa por COVID-19. Esto implica generar las condiciones adecuadas para dar los debidos cuidados a la persona contagiada, evitar la propagación del virus y garantizar su recuperación.

- Tener que trabajar. Muchas y muchos estudiantes tuvieron que buscar un empleo para solventar los gastos de casa, lo que afecta el tiempo que pueden dedicar a su formación profesional.

Como ya se ha dicho, la experiencia con la educación remota durante el confinamiento ha revelado las condiciones reales en las que las familias enfrentan la situación. Un reporte de la Oficina en México del Programa de las Naciones Unidas para el Desarrollo (PNUD, 2020) estima que alrededor del 55,7 \% de los hogares en México quedaron fuera del sistema de educación en línea que instrumentó la SEP, pues solo 44,3\% de los hogares cuenta con equipo de cómputo y $56,4 \%$ con internet; las proporciones son significativamente menores en las zonas rurales: $20,6 \%$ y $23,4 \%$, respectivamente; en los hogares de estratos altos, 9 de cada 10 tienen internet, y en los hogares de niveles bajos, solo 2 de cada 10 (Chávez, 2020). Estos datos evidencian la enorme brecha digital que existe en el país.

\section{La experiencia de los estudiantes de educación superior con la enseñanza remota}

Aunque al inicio del confinamiento, muchos estudiantes de todos los niveles consideraron que era una buena idea no tener que asistir presencialmente a los centros educativos, el desgaste que significa tomar las clases en línea y llevar a cabo sus actividades en modalidad remota no tardó en ocurrir. Una encuesta realizada por la organización Mextudia (2020), en la que participaron 110 estudiantes de nivel superior, 293 aspirantes y 89 estudiantes de otro nivel, arrojó los siguientes resultados:

- El 40 \% consideró que las clases en línea son peores que las presenciales, el 31 \% que son iguales, y el $29 \%$ que son mejores.

- El $38 \%$ dijo que su aprendizaje desde casa es peor que en la modalidad presencial, el $32 \%$ que es igual, y el $30 \%$ que es mejor.

- Entre las ventajas mencionaron los horarios más flexibles, la posibilidad de atender las necesidades de casa mientras estudian, el ahorro del tiempo que empleaban en el traslado y un ahorro monetario al no realizar los traslados. 
- El $72 \%$ valoró positivamente el trabajo de sus docentes, y el $28 \%$ opinó que este podría mejorar.

- El 89 \% dijo que continuaría con sus cursos el siguiente semestre, el 8,2 \% estaba indeciso y el 2,8 \% terminaría sus estudios este año.

- El 49,1 \% no quería continuar sus estudios desde casa, al 30 \% le gustaría y el $21,8 \%$ aún no lo sabía.

- El 53,4 \% tenía la expectativa de continuar estudiando en modalidad remota durante un tiempo largo, el 38,8 \% esperaba volver pronto a clases presenciales tomando medidas de protección, y el 7,8 \% no sabía.

Para entender cómo han vivido esta nueva realidad los alumnos y alumnas de la Universidad Autónoma Metropolitana Unidad Iztapalapa ante la implementación del Proyecto Emergente de Enseñanza Remota (PEER), se recuperan algunos testimonios tomados del conversatorio "Experiencias de docentes, alumnas y alumnos UAMI en PEER", transmitido el 25 de junio del 2020, en el canal de YouTube UAM Iztapalapa Oficial²:

[...] Me sentí nerviosa... Y tenía muchas preguntas sobre cómo se iba a desarrollar nuestro trimestre [...]. Creo que hay muchas ventajas que no estamos visualizando por estar pensando en lo negativo... (Alumna de Ingeniería Biomédica)

[...] Causó mucha incertidumbre porque los alumnos de posgrado dependemos de las instalaciones para poder realizar todo el trabajo experimental... [...]. En la continuación y culminación de los posgrados... Y que nos va a pegar en la eficiencia terminal porque CONACYT no perdona los tiempos para la evaluación de los posgrados adscritos al PNPC ni la vigencia de las becas... [...]. No todo es malo, creo que tenemos que encaminarnos a buscar hacer un ahorro para poder continuar... (Alumna del doctorado en Biotecnología)

Digamos que para mí, desde mi caso particular como extranjero, ha sido difícil para mí, hay que decir las cosas, psicológicamente fue un golpe duro porque yo llevo acá, en el país, seis meses, cuando empezamos el trimestre en diciembre y fue un primer trimestre presencial y un segundo trimestre que me coge por sorpresa. Yo vine a México, después de todos los problemas que tuve para poder estar acá, y decir, bueno, ahora tengo que estar en clases virtuales, porque yo siempre fui un fiel opositor de las clases virtuales en el sentido de que es importante [...] el contacto personal, el contacto físico, el poder estar cara a cara con el profesor, eso facilita muchísimo el diálogo, la retroalimentación, tantas cosas que por este medio es difícil. [...] fue una experiencia para dejar atrás muchos prejuicios... (Alumno de la maestría en Estudios Organizacionales)

2 El video del conversatorio completo puede verse en https://www.youtube.com/watch?v $=\_$z6IFQDbUJg 
Cuando señalan el PEER, como tal, me sentí un tanto más relajada porque, de alguna forma, yo trabajo y estudio... y por medio del trabajo se me dieron las herramientas para afrontar una cuestión de tanto tomar clases como dar clases en línea, entonces, de alguna forma eso me relajó. Sin embargo, también consideraba cuestiones como la familia, que también tiene que trabajar en línea a distancia y de alguna forma tener que acoplarnos a ello, porque de alguna forma uno tiene que organizar sus tiempos para no interrumpir los tiempos de los demás miembros de la familia... (Alumna de la licenciatura en Psicología Social)

En otros reportes, hubo estudiantes que consideraron que no aprenden de la misma manera en la modalidad virtual que en la presencial, especialmente en materias de disciplinas físico-matemáticas y ciencias naturales y exactas (Martínez Herrera, 2020), pues no pueden hacer las prácticas como en el laboratorio o en el aula de clase; también se quejaron de que sus profesores(as) les envían actividades en grandes volúmenes, así como de que les dan tareas que no entienden.

\section{Cómo evalúan los docentes de nivel superior la enseñanza remota}

Para los profesores y profesoras, el cambio repentino de los salones de clase físicos a las aulas virtuales, con poca o nula formación en el manejo de herramientas tecnológicas, implicó adaptarse rápidamente a las nuevas circunstancias, pues no solo tenían que dictar una clase a través de una plataforma, sino también adecuar los contenidos, diseñar nuevos materiales y recurrir a recursos didácticos variados para facilitar la labor docente, además de diseñar y planificar actividades más adecuadas para la modalidad remota. En el estudio realizado por la organización Mextudia (2020), los 22 docentes que participaron declararon lo siguiente:

- Las ventajas que encontraron en la educación en línea son la comodidad y el ahorro de tiempo en el traslado, que en ocasiones les tomaba más de dos horas al día.

- El 50 \% consideró que el desempeño de sus alumnas y alumnos era sobresaliente, el $27 \%$ no estaba conforme con dicho desempeño, y el $23 \%$ dijo que era adecuado.

- Para mejorar el desempeño de las alumnas y alumnos, sugirieron que tuvieran mayor apoyo tecnológico quienes no contaran con los recursos suficientes, y hacer las clases más interactivas.

- El $40,9 \%$ no deseaba que el próximo ciclo escolar se llevara a cabo a distancia, el $36,4 \%$ estaba de acuerdo con seguir enseñando desde casa, y el 22,7 \% estaba indeciso.

- Para evaluar, las profesoras y profesores usaron modalidades innovadoras, tales como exámenes, trabajos en video, videos en directo y trabajos escritos, entre otros. 
Asimismo, los docentes que no habían utilizado antes medios digitales, buscaron la forma de capacitarse para dar seguimiento a la labor que interrumpieron por la pandemia. Según un reporte de la Organización para la Cooperación y el Desarrollo Económicos (como se citó en G. Hernández, 2020), el 53 \% de los docentes en México necesita entrenamiento en nuevas tecnologías. Algunos testimonios de profesoras y profesores de la Universidad Autónoma Metropolitana Unidad Iztapalapa (UAM Iztapalapa Oficial, 2020) ilustran la forma como están enfrentando esta crisis:

La contingencia nos ha planteado nuevos retos a nuestro quehacer universitario. Si bien es cierto que para muchos de nuestros profesores es complicado plantearse un nuevo modelo de educación, ya que el actual, por lo cual ellos fueron contratados, es un modelo presencial de enseñanza-aprendizaje, el cual ha prevalecido desde su ingreso a la universidad, replantearse una nueva actividad sincrónica desde el punto de vista académico con un arranque de herramientas virtuales ha sido muy complicado y con tiempos muy limitados, ya que las plataformas virtuales comunes como Zoom o Classroom fueron de las más solicitadas por parte de los profesores... [...]. La propia Unidad Iztapalapa tiene sus propias versiones de plataformas como es VIRTUAMI, las cuales a algunos profesores se les hicieron muy laboriosas; al principio del trimestre no estaba muy claro cómo estaban las licencias del Zoom o de aulas virtuales; por lo tanto, fue muy complicado, casi, casi a unos días de arrancar el trimestre estar pendiente de las necesidades de cómo se iban a repartir las licencias virtuales, si por profesor o por área. (Profesor de la licenciatura en Biología de la Reproducción)

Desde que se declaró la pandemia, pues, la preocupación, digamos para toda la parte de autoridades, fue ¿y qué va a pasar con el trimestre?... [...] Ya empezábamos a vislumbrar trabajar de manera remota, no presencial... [...] las decisiones fueron acertadas, creo que hubo un exceso de apoyos, que me parece bueno, hubo seminarios, hubo ayudas; los profesores se quejaron de que les llegó demasiada información y no la podían procesar, pero creo que finalmente fue benéfico porque mal que bien arrancamos y los incidentes que hemos tenido han sido menores... (Profesor de Ingeniería Eléctrica)

En esa incertidumbre e inactividad que había en la UAM, a mí me generó mucha angustia y yo estaba muy preocupada, y después, ya cuando llegó el programa emergente, la verdad me dio mucho gusto... [...]. Yo siempre fui muy presencial y siempre desaproveché las oportunidades que nos ofrecía VIRTUAMI para empezar a tomar clases para hacer material virtual, pues, y siempre lo aplacé, seguramente pensando en que nunca lo iba a necesitar, y ahora estaba la necesidad, de ahora, ¿cómo le hago?, ¿qué pasó?, me tomé un montón de cursos, oí muchas pláticas; esto quiero resaltarlo, siempre me sentí muy acompañada por todos mis compañeros de sociales, pero también de CBI y de CBS... (Profesora de la División de Ciencias Sociales y Humanidades) 


\section{IMPACTO DEL CONFINAMIENTO EN LA SALUD MENTAL DE ESTUDIANTES Y PERSONAL ACADÉMICO}

El confinamiento ha tenido efectos psicosociales importantes en la vida de los estudiantes, los profesores y las personas de la población en general, ya que las situaciones que enfrentan y las sensaciones de ansiedad, estrés e incertidumbre son comunes en los diferentes grupos sociales. Nepote González et al. (2020) realizaron una encuesta en línea entre los meses de mayo y junio en la que participaron 9137 personas de todo el país, principalmente mujeres, la mayoría con estudios de nivel superior, con edades entre 27 y 59 años; asimismo, todos los participantes debían contar con internet y usar con frecuencia redes sociales, correo electrónico o WhatsApp como los principales medios para informarse ${ }^{3}$. Los resultados obtenidos muestran lo siguiente:

- Más del $90 \%$ conocía las medidas de prevención del contagio, el 50 \% los protocolos de atención médica y el 40 \% las medidas para tratar a una persona enferma por COVID-19 en casa.

- La mayor confianza entre la población la tenían los científicos (98\%) y el personal de salud (94\%); el gobierno obtuvo $46 \%$, los periodistas $54 \%$ y los líderes religiosos $74 \%$.

- De cada 10 participantes 6 reconocieron que la información que consultaron entre abril y mayo les fue de utilidad para tomar decisiones durante la crisis sanitaria.

- El 10 \% dejó de consultar noticias relacionadas con el COVID-19, tal vez como producto de la sobresaturación.

- Entre abril y mayo hubo un aumento de alrededor de cinco puntos porcentuales en las sensaciones negativas asociadas con la percepción de la información sobre el COVID-19, tales como "me agota", "me genera ansiedad" y "me confunde más".

- En contraste, "me ayuda a discernir lo que es verdadero y falso..." y "me ayuda a tomar decisiones..." disminuyeron alrededor de cuatro puntos en el mismo lapso de tiempo.

3 Los resultados de la investigación pueden consultarse en https://percepcioncovid19mexico.wordpress.com/

4 La ansiedad se relaciona con la anticipación de peligros futuros, indefinibles e imprevisibles; es una combinación de distintas manifestaciones físicas y mentales que no son atribuibles a peligros reales, sino que se revelan en forma de crisis, o bien como un estado persistente y difuso, pudiendo llegar al pánico; tiene un carácter anticipatorio, es decir, posee la capacidad de prever o señalar el peligro o amenaza para el propio individuo, confiriéndole un valor funcional importante (Sandín y Chorot, 1995, como se citó en Sierra, Ortega y Zubeidat, 2003). 
- Estos resultados sugieren que mantenerse informadas(os) no necesariamente se asocia con un mejor estado de ánimo, porque genera sensaciones negativas.

- En el $41 \%$ de las respuestas, se perciben sentimientos de frustración y miedo ante la emergencia sanitaria.

El Instituto de Investigaciones para el Desarrollo con Equidad de la Universidad Iberoamericana (EQUIDE, 2020) desarrolló y aplicó por teléfono la Encuesta de Seguimiento de los Efectos del COVID-19 en el Bienestar de los Hogares Mexicanos (ENCOVID-19) a 800 personas de 18 años o más. Sus resultados más importantes son los siguientes:

- El 64,4\% estaba en confinamiento.

- $\quad$ El 90,4 \% de quienes no se resguardaron lo hizo por razones de trabajo.

- El $\quad$ 37,7 \% reportó que uno o más integrantes del hogar perdió su empleo.

- El 34,5 \% no disponía de recursos suficientes para enfrentar la cuarentena.

- $\quad$ El $44,8 \%$ se sentía muy preocupado por la posibilidad de que su salud se viera afectada.

- $\quad$ El 29 \% dijo tener síntomas depresivos.

- $\quad$ El 32,4 \% declaró tener síntomas severos de ansiedad.

Las evidencias anteriores ilustran la forma como la pandemia trajo consigo una disrupción abrupta de la vida personal, familiar, laboral y comunitaria. Esta idea se encuentra plasmada también en el reporte derivado de un proyecto internacional denominado COVIDIStress, para el cual se aplicó en línea una encuesta entre el 30 de marzo y el 27 de abril del 2020, a la cual respondieron en México un total de 5007 personas en edad adulta residentes en el país (Contreras-lbáñez et al., 2020). Entre los resultados obtenidos se pueden mencionar los siguientes:

- Participaron 3607 mujeres (72 \%), 1352 varones (27\%) y 26 no declararon su sexo (1\%).

- Las mujeres reportaron niveles mayores de estrés ${ }^{5}$ que los varones (17,5 puntos y 15,4 puntos, respectivamente). Esto puede deberse a que ellas están

5 El estrés es una reacción fisiológica del organismo ante una situación que se percibe como amenazante o como una demanda excesiva. Es decir que depende, por un lado, de las demandas del medio (tanto externo como interno) y, por otro, de la persona (Selye, 1935, como se citó en Pérez Martínez, 2017), lo cual genera, según Oblitas (2004, como se citó en Naranjo Pereira, 2009), respuestas orgánicas en la persona cuando se enfrenta a una situación percibida como amenazante. Resulta importante anotar que el estrés es influenciado por situaciones diarias, eventos vitales, y por los medios y recursos de los que disponga la persona en un determinado momento (Remor, 2006). 
padeciendo más efectos emocionales, asociados con la triple y cuádruple jornada, y preocupaciones económicas.

- La cantidad de estrés se explica en casi $15 \%$ por la etapa de la vida que se encuentran viviendo las personas participantes.

- La escolaridad tuvo una relación inversa con el estrés: las personas con posgrado reportaron menores puntajes de estrés y quienes tenían bachillerato padecían mayor estrés.

- El grupo más estresado fue el de estudiantes, seguido de las personas sin empleo, de las empleadas a tiempo parcial, personas con autoempleo, personas con empleo de tiempo completo y, en último lugar, personas retiradas o jubiladas.

- Las personas solteras fueron las más estresadas, y después las que tenían otra condición; las menos estresadas eran las divorciadas y las que se encontraban casadas o en unión libre.

- El 67 \% declaró estar en aislamiento voluntario durante la contingencia; el 31 \%, que su vida siguió igual con cambios menores; el $2 \%$, que su vida continuó sin cambios, y el 0,2\% se encontraba en aislamiento médico.

- Las personas aisladas reportaron un nivel mayor de estrés, y las personas que dijeron seguir su vida sin cambios tuvieron el nivel más bajo de estrés.

- El nivel de estrés encontrado en México fue más alto que el reportado en otros países que participaron en el estudio.

Como ya se ha expuesto, las personas jóvenes, solteras y que tienen como ocupación principal ser estudiantes estaban entre las que reportaban los mayores niveles de estrés en los primeros meses del confinamiento producto de la pandemia por COVID-19. Según Bernardo Ng Solís, presidente de la Asociación Psiquiátrica Mexicana (como se citó en Rivera, 2020 y en Valadez, 2020), con la pandemia por COVID-19, cerca de la mitad de la población podría mostrar alguna manifestación psicopatológica, según la magnitud del evento y el grado de vulnerabilidad; y una proporción importante podría desarrollar el llamado "síndrome de la cuarentena", el cual incluye frustración, aburrimiento, nerviosismo, irritabilidad, ira, insomnio, agotamiento; además, se puede incrementar el miedo al contagio y a morir.

Un sondeo realizado en el mes de abril por la Federación de Estudiantes Universitarios entre la población estudiantil de la Universidad de Guadalajara, en el que participaron 14876 personas, sugiere que hay una afectación importante de la salud mental de la comunidad de estudiantes (Centro Universitario de Ciencias de la Salud, Universidad de Guadalajara, 2020). Los participantes reportaron tener una gran preocupación por la situación económica, así como incertidumbre académica y afectación emocional, al presentar tristeza, enojo y aburrimiento. 
Un reporte redactado por especialistas de tres universidades mexicanas (GonzálezJaimes, Tejeda-Alcántara, Espinosa-Méndez y Ontiveros-Hernández, 2020) revela que los 674 participantes, hombres y mujeres, con edades entre 18 y 43 años, quienes Ilenaron una encuesta en línea distribuida mediante Facebook, WhatsApp y Teams, presentaban síntomas de moderados a severos de estrés en el $31,9 \%$ de los casos, que el $36 \%$ tenía problemas para dormir, que el 9,5\% tenía disfunción social en la actividad diaria, el 5,9 \% síntomas psicosomáticos, y el 4,9\% síntomas depresivos, especialmente entre las mujeres y el grupo de las personas más jóvenes (de 18 a 25 años); además, el 40,3\% sintió ansiedad, lo que se observó mayormente en los varones, y el 31,9 \% sufrió estrés. Aproximadamente una cuarta parte de los participantes también tuvo dolor de cabeza, sensación de falta de control y poca satisfacción con sus actividades; un tercio reconoció sentirse agobiado, con nerviosismo, mal humor, menor actividad, dedicando más tiempo del usual para hacer tareas cotidianas, y con sentimientos de inutilidad; finalmente, más de la tercera parte tuvo problemas para dormir y el $42 \%$ mostró incapacidad para disfrutar las actividades cotidianas.

Un aspecto del que no se habla lo suficiente, que ha tenido un impacto negativo durante la cuarentena prolongada, ha sido la actividad física, que en el caso de los estudiantes disminuyó de manera drástica al iniciar el confinamiento, por la imposibilidad de salir y realizar ejercicio al aire libre, lo que tuvo como consecuencia un mayor sedentarismo (García Sánchez Madrid, 2020), y un impacto físico y emocional. En resumen, los estudiantes han experimentado durante el confinamiento: frustración, cansancio, mayor sedentarismo, estrés, enojo, incertidumbre y desesperanza, entre otras emociones, lo que provoca una clara afectación a su salud física y mental.

Por su parte, los académicos también han resentido el encierro, por tener que enfrentar el reto de la enseñanza remota con escasas o nulas habilidades para manejar plataformas tecnológicas, lo que ha producido, en muchos casos, una sensación de frustración. La nueva realidad educativa impuesta por la pandemia ha obligado a las profesoras y a los profesores a invertir más horas en la preparación de clases, en la producción de videos, de materiales y de actividades adecuados para las plataformas virtuales; así, además de impartir clases, ofrecen asesorías en horarios extendidos, califican y retroalimentan trabajos, y con frecuencia también cuidan niñas(os) pequeñas(os) o personas enfermas. Además, invierten sus propios recursos para realizar su trabajo: espacio, energía eléctrica, internet, computadora u otros dispositivos electrónicos.

El director del Centro de la Organización para la Cooperación y el Desarrollo Económicos (OCDE) en México manifestó que las clases a distancia tienen a los docentes estresados porque no todos ellos se habían enfrentado antes a un ambiente de enseñanza virtual, y porque se requiere de entrenamiento, capacitación y habilidades que no se adquieren de la noche a la mañana, lo que les ha llevado a trabajar a marchas forzadas 
o en doble jornada para aprender el uso de las nuevas herramientas y, al mismo tiempo, cumplir con su jornada regular de trabajo, ahora en línea (G. Hernández, 2020). En estas circunstancias, los docentes experimentan aumento de estrés, desgaste, agotamiento e incertidumbre.

El afrontamiento ante la enseñanza remota evidenció la carencia de habilidades tecnológicas de los profesores y profesoras, y también puso de manifiesto una brecha generacional no solo con sus alumnas y alumnos, sino también frente a sus colegas de mayor edad y más jóvenes. En estas circunstancias, coexisten personas que se pueden catalogar como baby boomers con otras pertenecientes a la generación X, millennials e incluso de la generación Z, y su relación con la tecnología difiere de manera significativa. Por esa razón, algunos docentes se adaptan de mejor manera a la situación, mientras que otros presentan dificultad para adecuarse a los avances tecnológicos, por lo que prefieren no emplear dispositivos y espacios virtuales para evitar sentirse opacados por estudiantes que los utilizan con mayor naturalidad (Vega Baeza y Durán Medina, 2013; Cortez Herrera, Serrano Fragoso y Fonseca Campos, 2020).

En el conversatorio titulado "Salud mental y docencia remota", convocado por la Universidad Autónoma Metropolitana (UAM, 2020), transmitido el 4 de septiembre por la página de Facebook de la misma institución, el doctor Eduardo Peñalosa Castro, rector general de esa casa de estudios, sostuvo que el aislamiento, los temores, las dificultades cotidianas y las dinámicas de los procesos pedagógicos pueden aumentar los riesgos de algunos trastornos - cuadros de estrés repetitivo o de ansiedad- o exacerbar sus efectos.

\section{Diferencias en el impacto en la salud mental por condición de género}

La pandemia también ha puesto en evidencia la desigualdad que existe entre distintos grupos sociales ${ }^{7}$. Entre las consecuencias que se prevé que pueden afectar a las niñas, a las adolescentes y a las jóvenes en el ámbito escolar, durante y después de la pandemia, están las siguientes: un aumento en la deserción escolar, menores posibilidades de volver a la escuela, una mayor tasa de embarazos forzados, mayor violencia por razones

6 La OMS (como se citó en Médicos del Mundo España, 2018) define a la salud mental como "un estado de bienestar en el cual el individuo es consciente de sus propias capacidades, puede afrontar las tensiones normales de la vida, puede trabajar de forma productiva y fructífera, y es capaz de hacer una contribución a su comunidad".

7 Los investigadores de la Universidad Autónoma de Barcelona (UAB) condujeron un estudio internacional que señala que en la cuarentena las mujeres jóvenes con bajos ingresos son el perfil poblacional en mayor riesgo, al reportar $53 \%$ de síntomas de depresión, $45 \%$ de somatización y un $40 \%$ de ansiedad. En cambio, el perfil en menor riesgo son los adultos mayores hombres con altos ingresos, quienes reportaron $11 \%$ de síntomas de ansiedad, $11 \%$ de depresión y $2 \%$ en somatización (Pontificia Universidad Javeriana, 2020). 
de género, mayor tiempo de dedicación a los cuidados de otras personas, afectaciones graves a la salud física, mental, sexual y reproductiva, y una menor participación en espacios públicos y privados (UNESCO, ONU Mujeres y Plan Internacional, 2020). Con esto, se pone en riesgo el logro de los Objetivos del Desarrollo Sostenible (ODS), en particular el ODS4, que se refiere al acceso a una educación de calidad e inclusiva, y el ODS5, relacionado con reducir la brecha de género (Amor Alameda, 2020), ya que la evidencia muestra que, ante una crisis humanitaria, las niñas y las mujeres sufren una mayor vulnerabilidad.

Las docentes no escapan a esta realidad, ya que, de acuerdo con la Comisión Interamericana de Mujeres de la Organización de Estados Americanos (OEA-CIM, 2020), la emergencia derivada del COVID-19 está provocando impactos específicos sobre las mujeres y profundizando las desigualdades de género existentes, tanto al interior de los hogares como fuera de ellos. En este período, las mujeres no solo tienen que realizar más trabajo, sino que también están más expuestas a la violencia y a un menor acceso a servicios de salud, con una mayor afectación en su salud mental. La jornada laboral en modalidad remota o virtual ha intensificado las desigualdades, igual que los mandatos y estereotipos de género, entre otras razones, porque las mujeres dedican más tiempo al cuidado material, al cuidado económico y al cuidado psicológico de los miembros de la familia ${ }^{8}$, y también porque, comparativamente, las mujeres docentes tienen menos habilidades para el manejo de recursos tecnológicos que los varones, lo que hace más difícil para ellas conciliar la vida laboral, personal y familiar durante la pandemia (Enríquez, 2020; Instituto Nacional de las Mujeres, 2020).

Al ser las mujeres las que más trabajan en esta temporada de COVID-19, como madres, profesionistas y cuidadoras, están más proclives a experimentar el "síndrome del quemado" o burnout, el cual solía ser exclusivo del ambiente laboral, pero que ahora se extiende hasta el hogar (“¿Cómo evitar el síndrome del burnout en cuarentena?", 2020). Todo esto se asocia, frecuentemente, con ansiedad, hostilidad, ira, depresión o tristeza. Además, se produce una alteración del comportamiento, que abre paso al desarrollo de hábitos perjudiciales.

Así, para las mujeres docentes, es difícil mantener una vida profesional plena, ejercer su derecho al cuidado de su familia, el libre desarrollo de su personalidad, su autocuidado, su formación, su descanso, el disfrute de su ocio y el tiempo libre (Enríquez, 2020). El confinamiento obstaculiza su ejercicio pleno de los derechos humanos, la

8 Un estudio realizado en España en los años 2000-2001, en el que se analizaron cuatro tareas domésticas y ocho tareas docentes, arrojó que las maestras dedicaban más tiempo a tareas domésticas que los maestros, que más de un tercio de los maestros atribuye la responsabilidad de las mismas a sus compañeras, mientras que muy pocas maestras (entre un $0 \%$ y un 2,3 \%) atribuyeron tal responsabilidad a sus compañeros (Rodríguez Hernández y Santana Bonilla, 2006). 
equidad de género y la justicia social. Por ejemplo, el informe del Programa de Naciones Unidas para el Desarrollo (PNUD) advirtió que la pandemia interrumpió gravemente el acceso a servicios de salud sexual y reproductiva, y también limitó la capacidad de las autoridades para responder a la violencia de género. Enríquez (2020) sostiene:

[...] desde el inicio de las medidas de aislamiento social, la saturación de centros de salud y el cierre de escuelas y guarderías, las cargas adicionales de trabajo de cuidados han recaído mayoritariamente en las mujeres, quienes, por lo general, tienen la responsabilidad socialmente construida de atender a familiares enfermos; personas mayores o con discapacidades, y la tutela de niñas, niños y adolescentes.

Se calcula que el tiempo destinado al trabajo de cuidados es de 55 horas semanales en promedio en México, y este es asumido principalmente por mujeres (ENUT, 2014, como se citó en Enríquez, 2020).

Las mujeres que realizan trabajo académico, así como las alumnas y otro tipo de trabajadoras universitarias, han tenido que trabajar, estudiar y cuidar al mismo tiempo, con jornadas intensas, que afectan el tiempo del que disponen para realizar el trabajo remunerado y no remunerado, así como para atender su salud e integridad física y emocional. Enríquez (2020) cita una encuesta realizada por el Centro de Investigaciones y Estudios de Género de la UNAM en el 2019 sobre el impacto de las labores domésticas y cuidados en las trayectorias de las mujeres universitarias, la cual mostró que las académicas dedicaban un promedio de 24,1 horas semanales a las labores domésticas, mientras que los varones dedicaban 15,6 horas semanales a dichas tareas.

Los varones suelen mantenerse distantes de los espacios domésticos, por lo que uno de los impactos que tuvo para ellos la pandemia fue el confinamiento en casa, con la familia, y convivir con esta a tiempo completo, lo cual ha significado para algunos "reconectarse" con sus esposas, hijas e hijos (Maestría en Estudios de Género, Universidad Autónoma de Nayarit, 2020), aunque reconocen que esto les ha permitido respirar un poco y modificar la fuerte dinámica de trabajo que tenían antes de la pandemia, reincorporarse a la dinámica de sus hogares y dejar de ser solo "visitantes nocturnos". El confinamiento les ha llevado, en opinión de algunos, a repensar relaciones que vivían "a la distancia". Reconocen que durante el tiempo que no salieron de sus domicilios se sintieron encerrados, y llegaron a resentir el aislamiento y a experimentar la necesidad de salir.

9 La Red Nacional de Refugios (RNR, 2020) reportó que "durante los primeros 5 meses de contingencia por covid-19 las atenciones en Refugios, Centros de Atención Externa, Casas de Emergencia y de Transición de la RNR se incrementaron 68 \% [...] 4 de cada 10 mujeres que se comunicaron a la RNR refirieron sufrir violencia física y el $51 \%$ de las hijas e hijos fueron víctimas de agresiones mientras se quedaban en casa protegiéndose por la pandemia [...]". 
Algunos docentes varones retomaron recientemente una parte de sus labores académicas, con medidas de protección para evitar el contagio. Reconocen que al principio de la pandemia se confinaron en sus domicilios, pero, una vez que las actividades se fueron reactivando, comenzaron a salir, dejando a sus esposas al cuidado de sus hijos e hijas, casi hasta sentir que han recuperado su "vida cotidiana". Acostumbrados a trabajar en sus unidades académicas, ya sea en los cubículos o en la biblioteca, a hacer trabajo de campo en comunidades, el encierro del inicio de la pandemia los sacó abruptamente de sus rutinas, y dedicaron unas semanas a solo estar con su familia y a tratar de procesar el cambio drástico que estaban experimentando. Tuvieron que aprender a organizar y gestionar el tiempo para realizar sus actividades académicas, y participar en el cuidado y el acompañamiento en la educación de sus hijas e hijos, así como en las tareas del hogar. Reconocen que esa nueva dinámica es cansada y desgastante, y también cayeron en la cuenta de que "no pueden controlar los tiempos de la casa", y que no podían concentrarse en lecturas y redacción de documentos.

Reconocieron que las actividades aumentaron mucho, por la preparación de clases en la modalidad virtual, así como por la producción de clips, videos y otros materiales; en algunos casos, conviven con parejas que también se dedican a la academia, lo que les demanda colaborar más en las tareas domésticas. No han podido organizar como quisieran sus horarios, y van atendiendo las necesidades como se van presentando; manifestaron que han tenido que adaptarse y organizarse de manera distinta para avanzar en sus tareas académicas, siendo conscientes de que no se pueden lograr los mismos objetivos que en las condiciones existentes antes de la pandemia.

Entre las desventajas o afectaciones del confinamiento, mencionaron la falta de contacto con alumnas y alumnos, con colegas, la escasa posibilidad de realizar trabajo colaborativo, la mayor dificultad para realizar trámites administrativos, extrañar el contacto cara a cara y el ambiente de convivencia que tenían en la universidad, falta de concentración, no contar con un espacio en casa para la realización de las labores académicas, el retraso de los proyectos de investigación, la dificultad para coordinar con otros docentes e investigadores, la imposibilidad de abrir nuevas carreras o de actualizar los programas de estudio existentes.

Los participantes en el conversatorio "Académicos desde casa" (Maestría en Estudios de Género, UAN, 2020) dijeron contribuir de manera activa y equitativa en las labores domésticas (barrer, trapear, lavar trastos y ropa, realizar trabajos escolares con sus hijas e hijos, hacer compras de víveres, realizar pagos en los bancos), y estar más presentes en el cuidado de personas adultas mayores, actividades que reconocen que no habían hecho con tanta frecuencia antes del confinamiento; dejaron entrever, sin embargo, que las mujeres (sus parejas) son quienes se encargan de preparar la comida casi en todos los casos y de cuidar a las niñas y los niños, y también que, en cuanto las 
condiciones lo permiten, salen de casa para atender sus propios pendientes, dejando el trabajo doméstico mayormente a cargo de las mujeres, quienes también están realizando trabajo remunerado desde sus hogares. Para varios de ellos, no fue fácil coordinar los tiempos del trabajo académico con el trabajo doméstico y el cuidado de sus familiares mayores. Una vez que logran ajustarse, hay académicos que no quieren volver a la dinámica saturada de pendientes docentes, pues desean seguir conviviendo con su familia como lo han hecho durante el confinamiento. Asimismo, el confinamiento ha sido un desafío para la convivencia con la familia en espacios limitados, y tuvieron que negociar los conflictos a través del diálogo para preservar un ambiente favorable con la pareja, las hijas y los hijos, asignándoles mayores responsabilidades para un reparto más equitativo de las tareas domésticas.

\section{Posibles beneficios de la educación en modalidad remota}

Si bien las clases presenciales son irremplazables, la enseñanza remota también ha tenido ventajas. En primera instancia, el no exponer la salud de docentes y estudiantes, y cuidarles de la manera más eficaz que existe para no contagiarse de COVID-19, que es manteniéndose resguardadas(os) en casa (distanciamiento social). En segundo lugar, ha sido positivo no postergar la educación para la formación profesional de alumnos de licenciaturas o posgrados, propiciando un aprendizaje que incluye actividades lúdicas, creativas e innovadoras, incorporando internet como un medio de comunicación básico y relevante para el aprendizaje moderno. Otro beneficio que el ciberespacio ofrece es la flexibilidad con la que se puede trabajar (Vega Baeza y Durán Medina, 2013), es decir, los alumnos y alumnas pueden escoger los horarios que consideren convenientes para revisar los contenidos o realizar las actividades de sus materias; además, les permite trabajar en tiempo real o asincrónico con otros compañeros, y por medio de videoconferencias se ha podido emular las clases presenciales, e incluso desempeñar una actividad laboral.

Para los profesores y profesoras, la enseñanza remota les ha dado flexibilidad para organizar su trabajo, les ha demandado creatividad para la creación de contenidos y la programación de actividades, el aprender habilidades nuevas para el manejo de herramientas y recursos digitales, y les ha permitido pasar más tiempo con sus familias, o bien dedicar un espacio a actividades o aficiones que antes no podían realizar, como ejercicio, meditación, cocina, jardinería y otros, además de reducir el desgaste y el estrés provocados por los tiempos de traslado a la universidad.

Asimismo, se ha dado una nueva relación entre alumnos y profesores, caracterizada por una interacción más personal y directa cuando las condiciones lo permiten; mediante el uso de recursos tecnológicos se favorece la integración y la cooperación, creando una interacción directa y la socialización de conocimientos, desarrollando una 
inteligencia colectiva, que podemos observar en las participaciones activas en los foros en línea y en los grupos de discusión, entre otros espacios. Esto implica que el papel de los estudiantes y del profesor o profesora toman otro horizonte: superando el tradicionalismo, los docentes dejan de ser expositores y pasan a ser mediadores del proceso educativo, mientras que los alumnos y alumnas asimilan, reflexionan y hacen suyo el conocimiento (Hermann Acosta, 2011). De este modo, a pesar de todos los inconvenientes que ha traído consigo la educación en modalidad remota, vale la pena ponderar también los beneficios.

\section{Elementos para mantener el bienestar psicológico ${ }^{10}$ y reducir la brecha de género durante el confinamiento}

Algunas acciones que se pueden implementar para tener una experiencia menos estresante durante el confinamiento y tratar de reducir la carga excesiva de trabajo son las siguientes:

- Establecer una rutina. Se recomienda fijar horarios para las actividades del día a día, y tratar de apegarse a estos, para mantener una sensación de orden.

- Definir responsabilidades. Asignar a los miembros de la familia labores para no sobrecargar solo a algunos, especialmente a las mujeres.

- Compartir las tareas domésticas y las labores de cuidado de otras personas, y con ello fomentar la equidad.

- Establecer acuerdos para colaborar y apoyar a las personas con las que se convive durante el confinamiento.

- Procurar resolver los conflictos que se presentan con una actitud empática.

- Poner límites. Mantener espacios y momentos de intimidad.

- Mantener hábitos saludables de sueño y alimentación.

- Realizar actividad física, eligiendo opciones adecuadas para el espacio y el tiempo del que se dispone.

- Destinar tiempo al ocio y al esparcimiento.

- Reservar tiempo para actividades religiosas o espirituales, si se consideran importantes.

- Mantener el contacto con familiares y amigas(os).

10 Existen documentos con recomendaciones para que las familias cuenten con recursos que les permitan afrontar el confinamiento, por ejemplo, el de los Centros de Apoyo a las Familias del Ayuntamiento de Madrid (2020). 
- Establecer redes sociales de apoyo. Identificar quiénes pueden ofrecer consejos, soporte emocional, financiero, material, informativo, etcétera, y tener a la mano su contacto en caso de requerirlo.

- Elaborar un plan de acción para el caso de que una persona del núcleo familiar adquiera coronavirus. Saber cómo actuar ayudará a reducir los niveles de ansiedad en los miembros de la familia.

- Conversar y acordar las medidas que deben tomar los miembros de la familia que se vayan reincorporando a sus actividades para evitar contagios.

\section{CONCLUSIONES}

En México, las clases en línea han sido un evento difícil que ha modificado nuestros hábitos y rutinas, así como la forma de tomar y ofrecer clases, a través del nuevo uso que adquirieron las tecnologías, aun cuando antes de la pandemia nuestras sociedades no estaban preparadas para el afrontamiento de las nuevas e inesperadas exigencias. Esto, en un inicio, generó angustia e incertidumbre, entre otras afectaciones a la salud mental, por las condiciones poco adecuadas que teníamos en nuestros hogares, con la falta de espacio, iluminación, ruido y carencia de recursos tecnológicos, especialmente en el caso de los estudiantes (Chacón, 2020). Como ha quedado expuesto, la carga de trabajo excesivo ha afectado especialmente a las mujeres por su rol en la familia como cuidadoras de los hijos, de personas enfermas y del hogar, exponiendo la desigualdad de género que prevalece en nuestra sociedad; algunos académicos han participado poco a poco en las tareas domésticas y de cuidado, aunque parecen gozar de mayores oportunidades para salir del confinamiento, o para regresar a una cotidianidad lo más parecida posible en las circunstancias actuales al estado previo a la pandemia. Asimismo, la convivencia familiar, al ser de tiempo completo, ha requerido del uso de habilidades de negociación de conflictos y de mediación de la expresión emocional, que se han tenido que desarrollar en el transcurso del confinamiento; los varones se han involucrado, en ocasiones en forma involuntaria, en el cuidado de los hijos y de las personas mayores, lo que les acerca afectiva y emocionalmente a sus familias, lo que constituye una experiencia emocional relativamente novedosa para ellos.

Es necesario que, a partir de esta experiencia, se valore la necesidad de la participación igualitaria de las mujeres en los mecanismos de respuesta y recuperación de la crisis del COVID-19, la cual es importante en sí misma por razones de igualdad, justicia y democracia, sobre todo considerando que las mujeres representan la mitad de la población en todos los países de América Latina, aportan perspectivas distintas y asumen con mayor liderazgo las necesidades diferenciadas de las mujeres. Es indispensable la participación igualitaria de las mujeres en la toma de decisiones para ofrecer respuestas efectivas y apropiadas a la crisis (Instituto Nacional de las Mujeres, 2020). 
Algunos autores afirman que la educación virtual, remota o a distancia, era ya una tendencia que no hizo sino fortalecerse durante la pandemia y que permanecerá después de que este episodio de salud concluya. Las habilidades adquiridas tanto por la comunidad de estudiantes como por la de profesores constituyen recursos valiosos para enfrentar las demandas del futuro. Falta, sin embargo, imaginar un nuevo orden, más justo y equitativo, que permita a mujeres y varones reducir las brechas de género y gozar de sus plenos derechos, lo que sin duda impactará positivamente en su salud mental, pues cuando se comparten las tareas de crianza y de cuidado, y las labores domésticas se distribuyen de manera más equitativa, el estrés disminuye; cuando se reduce la carga excesiva de trabajo y se deja espacio para el descanso, el esparcimiento y la actividad física, mejoran los hábitos de sueño y la ansiedad también desciende; asimismo, cuando se cuida la alimentación y se restringe el consumo de alimentos y sustancias nocivas para la salud, hay una mayor sensación de bienestar.

Los expertos consideran que, de no desarrollar estrategias preventivas y de autocuidado durante el confinamiento, la siguiente pandemia será una relacionada con la salud mental, pues prevalecerán los cuadros de ansiedad, estrés, angustia, desesperanza e incluso depresión, los cuales pueden resultar discapacitantes ("Confinamiento podría provocar ansiedad o depresión en 45 \% de los mexicanos", 2020). De ahí la importancia de tomar acción inmediata para proteger a nuestras comunidades docentes y de estudiantes, que se ven expuestas a niveles importantes de ansiedad y estrés durante el prolongado período de aislamiento social.

Este peculiar proceso de enseñanza y aprendizaje ha provocado el rechazo de una parte de los estudiantes, así como de algunos docentes (Martínez Herrera, 2020). Sin embargo, también se reconocen las ventajas de la enseñanza remota: flexibilidad, creatividad, desarrollo de la inteligencia colectiva, trabajo colaborativo, una resignificación del rol de los profesores y de los estudiantes, y un replanteamiento del esquema tradicional de la enseñanza. Es real que en la modalidad virtual no se aprende de la misma manera que cuando se tiene la posibilidad de hacerlo presencialmente; sin embargo, la experiencia puede dejar como saldo un aprendizaje invaluable para todas las personas involucradas y una capacidad de resiliencia muy valiosa para enfrentar los retos venideros. La tarea docente en el futuro se verá muy beneficiada y enriquecida si nos proponemos ser personas más comprensivas, más flexibles, más pacientes, más solidarias, más empáticas.

A seis meses de iniciado el confinamiento, aún es incierto cuándo podremos volver a encontrarnos como solíamos hacerlo antes de la pandemia. Parece ser un hecho que no retornaremos durante mucho tiempo al estilo de vida que teníamos antes de la contingencia; la incertidumbre será lo que marque el futuro inmediato y el mediano plazo. Los seres humanos tenemos la capacidad para adaptarnos y hacer frente a la incertidumbre 
que acompañará nuestro quehacer familiar y laboral mientras se desarrolla una vacuna o un tratamiento confiable contra el SARS-CoV-2. El trabajo académico no escapa a esa circunstancia, y las comunidades escolares harán uso de todas sus capacidades y recursos para adecuarse a la nueva realidad, con la ventaja y la fortaleza adquiridas con esta experiencia, que sin duda marcará la vida de varias generaciones durante mucho tiempo.

\section{REFERENCIAS}

Amor Alameda, A. (23 de abril del 2020). Igualdad de género y educación en tiempos del coronavirus. El País. Recuperado de https://elpais.com/elpais/2020/04/17/ planeta_futuro/1587133877_135712.html

Centro Universitario de Ciencias de la Salud, Universidad de Guadalajara. (20 de abril del 2020). Padecen estudiantes problemas de ansiedad ante confinamiento. Recuperado de http://www.cucs.udg.mx/noticias/archivos-de-noticias/padecen -estudiantes-problemas-de-ansiedad-ante-confinamiento

Centros de Apoyo a las Familias del Ayuntamiento de Madrid. (2020). Guía para la convivencia familiar durante la crisis del COVID-19. Recomendaciones de los Centros de Apoyo a las Familias del Ayuntamiento de Madrid. Recuperado de https://www.madrid.es/UnidadesDescentralizadas/InfanciayFamilia/ EntidadesyOrganismos/CAF/EstadoAlarmaGuias/GuiaparalaConvivencia FamiliarCAF.pdf

Chacón, M. (5 de junio del 2020). Salud mental de los estudiantes, una víctima del aislamiento. El Tiempo. Recuperado de https://www.eltiempo.com/vida/educacion/ como-esta-la-salud-mental-de-los-estudiantes-durante-el-aislamiento5038921

Chávez, V. (17 de agosto del 2020). Educación online de SEP dejó "fuera" a 55,7 \% de alumnos en México. El Financiero. Recuperado de https://www.elfinanciero.com. $\mathrm{mx} /$ nacional/educacion-online-de-sep-inaccesible-para-55-7-de-alumnos-enmexico

Comisión Interamericana de Mujeres, Organización de Estados Americanos (OEA-CIM). (2020). COVID-19 en la vida de las mujeres. Recuperado de http://www.oas.org/ es/cim/docs/ArgumentarioCOVID19-ES.pdf

¿Cómo evitar el síndrome del burnout en cuarentena? (30 de junio del 2020). Infobae. Recuperado de https://www.infobae.com/tendencias/talento-y-liderazgo/2020 /06/30/como-evitar-el-sindrome-del-burnout-en-cuarentena/ 
Confinamiento podría provocar ansiedad o depresión en $45 \%$ de los mexicanos. (3 de abril de 2020). Agencia EFE. Recuperado de https://www.efe.com/efe/america/ sociedad/confinamiento-podria-provocar-ansiedad-o-depresion-en-45-delos-mexicanos/20000013-4212280

Contreras-Ibáñez, C. C., Flores González, R., Reynoso-Alcántara, V., Pérez-Gay Juárez, F., Castro López, C., y Martínez, L. (2020). Estrés, al inicio de la pandemia por covid19. Entorno UDLAP, edición especial, 102-119.

Coronavirus en México: confirman los primeros casos de COVID-19 en el país. (29 de febrero del 2020). BBC News Mundo. Recuperado de https://www.bbc.com/ mundo/noticias-america-latina-51677751

Cortez Herrera, P., Serrano Fragoso, M., y Fonseca Campos, J. (2020). Competencias necesarias para un profesor actual: de clases presenciales a clases en línea. Recuperado de https://www.researchgate.net/publication/343486240_COM PETENCIAS_NECESARIAS_EN_UN_PROFESOR_ACTUAL_DE_CLASES_ PRESENCIALES_A_CLASES_EN_LINEA

Enríquez, L. (2 de septiembre del 2020). Mujeres universitarias y la sobrecarga del trabajo de cuidados durante la pandemia. Animal Político. Recuperado de https:// www.animalpolitico.com/blog-invitado/mujeres-universitarias-sobrecargatrabajo-de-cuidados-pandemia/

Escotto, V. (31 de marzo del 2020). Estos son los retos de la educación a distancia ante un panorama de coronavirus en México. Business Insider México. Recuperado de https://businessinsider.mx/esretos-educacion-a-distancia-ante-un-panorama -de-coronavirus-en-mexico-blended-learning/

Estrada Iguíniz, M. (2010). Convivencia forzosa. Experiencias familiares durante la emergencia sanitaria por el virus de la influenza humana A (H1N1) en la Ciudad de México. Desacatos, 32, 109-118. Recuperado de http://www.scielo.org.mx/pdf/ desacatos/n32/n32a8.pdf

García Sánchez Madrid, M. (27 de abril del 2020). Los efectos del confinamiento en los universitarios, a examen. Agencia EFE. Recuperado de https://www.efe.com/ efe/espana/efefuturo/los-efectos-del-confinamiento-en-universitarios-aexamen/50000905-4232304

Gobierno de México. (2020). Jornada Nacional de Sana Distancia. Recuperado de https:// www.gob.mx/cms/uploads/attachment/file/541687/

González-Jaimes, N. L., Tejeda-Alcántara, A. A., Espinosa-Méndez, C. M., y OntiverosHernández, Z. O. (2020). Impacto psicológico en estudiantes universitarios mexicanos por confinamiento durante la pandemia por covid-19. Preprint, versión 1. https://doi.org/10.1590/SciELOPreprints.756 
Hermann Acosta, A. (2011). Pedagogía del ciberespacio: hacia la construcción de un conocimiento colectivo en la sociedad red. Sophia: Colección de Filosofía de la Educación, 11, 83-103.

Hernández, F. (1 de julio del 2020). 49 \% de los mexicanos cree que el home office aumenta la productividad. Centro Urbano. Recuperado de https://centrourbano. com/2020/07/01/mexicanos-home-office-productividad/

Hernández, G. (16 de mayo del 2020). \#DíaDelMaestro: La odisea de la educación virtual forzada por el coronavirus. Factor Capital Humano. Recuperado de https:// factorcapitalhumano.com/carrera/diadelmaestro-la-odisea-de-la-educacionvirtual-forzada-por-el-coronavirus/2020/05/

Hernández Armenta, M. (12 de junio del 2020). El desencanto del home office: trabajar a distancia no es lo que todos esperaban. Revista Forbes México. Recuperado de https://www.forbes.com.mx/tecnologia-desencanto-homeoffice/

Hernández, G., y Juárez, B. (2020). Home office y el experimento en tiempos de coronavirus, ¿llegó para quedarse? Factor Capital Humano. Recuperado de https:// factorcapitalhumano.com/mundo-del-trabajo/home-office-y-el-experimentoen-tiempos-de-coronavirus-llego-para-quedarse/2020/04/

Instituto de Investigaciones para el Desarrollo con Equidad. (2020). La Ibero presenta la encuesta de seguimiento de los efectos del covid en el bienestar de los hogares mexicanos \#ENCOVID19. Recuperado de https://ibero.mx/sites/default/files/ comunicado_encovid-19_completo.pdf/

Instituto Nacional de Estadística y Geografía, Secretaría de Comunicaciones y Transportes e Instituto Federal de Telecomunicaciones. (2020). En México hay 80,6 millones de usuarios de internet y 86,5 millones de usuarios de teléfonos celulares: ENDUTIH 2019 [comunicado de prensa]. Recuperado de https://www.inegi.org. mx/contenidos/saladeprensa/boletines/2020/OtrTemEcon/ENDUTIH_2019.pdf/

Instituto Nacional de la Juventud (INJUVE). (2018). Encuesta de tendencias juveniles 2018. Recuperado de https://www.injuve.cdmx.gob.mx/storage/app/uploads/ public/5c8/eab/e5b/5c8eabe5b9ef1297714358.pdf

Instituto Nacional de las Mujeres. (2020). La desigualdad de género llegó mucho antes que la pandemia. Recuperado de https://www.gob.mx/inmujeres/articulos/ la-desigualdad-de-genero-llego-mucho-antes-que-la-pandemia?idiom=es

Juárez, B. (23 de junio del 2019). Reglamentan home office como modalidad formal de trabajo en México. Factor Capital Humano. Recuperado de https:// factorcapitalhumano.com/leyes-y-gobierno/reglamentan-home-office-comomodalidad-formal-de-trabajo-en-mexico/2019/06/ 
La contingencia redujo la movilidad en $67 \%$ a nivel nacional, según el gobierno. (21 de abril del 2020). Expansión Política. Recuperado de https://politica.expansion. $\mathrm{mx} / \mathrm{mexico} / 2020 / 04 / 21 /$ las-contingencia-redujo-la-movilidad-en-67-a-nivelnacional-segun-el-gobierno

Maestría en Estudios de Género, Universidad Autónoma de Nayarit (UAN). (Productor). (2020). Conversatorio "Académicos desde casa" [archivo de video]. Recuperado de https://www.facebook.com/MEGUAN1/videos/698614990979170/

Martínez Herrera, G. (2020). La enseñanza y el aprendizaje fuera del aula en tiempos de confinamiento. UGreka! Recuperado de https://www.ugto.mx/eugreka/contribu ciones/225-la-ensenanza-y-el-aprendizaje-fuera-del-aula-en-tiempos-deconfinamiento

Médicos del Mundo España. (10 de octubre del 2018). ¿Qué es la salud mental y el apoyo psicosocial? Recuperado de https://www.medicosdelmundo.org/actualidad-ypublicaciones/noticias/que-es-la-salud-mental-y-el-apoyo-psicosocial

Mextudia. (2020). ¿Cómo afectó el confinamiento a estudiantes y profesores? Recuperado de https://mextudia.com/como-afecto-el-confinamiento-a-estudiantes-y-profe sores/

Millet, E. (22 de marzo del 2020). La pandemia de coronavirus pone a prueba a la familia. La Vanguardia Magazine. Recuperado de https://www.lavanguardia.com/ magazine/20200322/474261347020/pandemia-coronavirus-familia-parentingconfinamiento.html

Moreno, T. (8 de enero del 2020). Regresan a clases más de 32 millones de alumnos. El Universal. Recuperado de https://www.eluniversal.com.mx/nacion/regresan -clases-mas-de-32-millones-de-estudiantes

Naranjo Pereira, M. L. (2009). Una revisión teórica sobre el estrés y algunos aspectos relevantes en el ámbito educativo. Revista Educación, 33(2), 171-190.

Navarrete, S. (12 de junio del 2020). Regular el home office, el pendiente que el covid-19 destapó en la CDMX. Expansión Política. Recuperado de https://politica.expan sion.mx/cdmx/2020/06/12/regular-el-home-office-el-pendiente-que-el-covid19-destapo-en-la-cdmx

Nepote González, A. C., Posada de la Concha, J. M., Tarhuni Navarro, D., Varguez Ramírez, M., Hernández-Stefanoni, J. L., y Saldívar Chávez, M. A. (2020). COVID-19, lo que los mexicanos percibimos de esta enfermedad. Saber Más. Revista de Divulgación de la Universidad Michoacana de San Nicolás de Hidalgo. Recuperado de https://www.sabermas.umich.mx/secciones/articulos/891covid-19-lo-que-los-mexicanos-percibimos-de-esta-enfermedad.html?fbclid =IwAR0vuq34Y-CKzMWi5_RC-Rr-7YAEBN39vB0zK8BJY29Kd9cPU3mqUK41afk 
Organización Mundial de la Salud (OMS). (2020). Brote de enfermedad por coronavirus (COVID-19). Recuperado de https://www.who.int/es/emergencies/diseases/novel -coronavirus-2019

Pérez Martínez, J. (2017). Capítulo 1. ¿Qué es el estrés? En Trata el estrés con PNL (pp. 19-22). Madrid: Centro de Estudios Ramón Areces. Recuperado de https:// www.cerasa.es/media/areces/files/book-attachment-1677.pdf

Pontificia Universidad Javeriana. (6 de agosto del 2020). Ansiedad y depresión, "verdugos" de los jóvenes en la pandemia. Pesquisa Javeriana. Recuperado de https://www. javeriana.edu.co/pesquisa/tag/salud-mental/

Programas de las Naciones Unidas para el Desarrollo (PNUD). (13 de julio del 2020). ¿Qué significa la COVID-19 para las mujeres? [mensaje en un blog]. Recuperado de https://www.undp.org/content/undp/es/home/blog/2020/what-does-coronavirus-mean-for-women.html

Red Nacional de Refugios (2020). De los discursos a los hechos: "Violencias contra las mujeres y la ausencia de políticas gubernamentales para garantizar una vida libre de violencias antes y después del COVID-19". Ciudad de México: Autor. Recuperado de https://drive.google.com/file/d/10dKgbLLy335UFZdBxV5cVaX DcQ1K2I1/view?fbclid=IwAR1AjlLYnm5c3Jq_JrHISs36Gz6QvE0YUUj9u_uWZv_ oyWJbGCiaYUTnOLs

Remor, E. (2006). Psychometric properties of a European Spanish Version of the Perceived Stress Scale (PSS). The Spanish Journal of Psychology, 9, 86-93.

Rivera, R. (9 de abril del 2020). Covid-19 puede provocar condición patológica de ansiedad. Milenio. Recuperado de https://www.milenio.com/content/salud-y-nutricion/ evita-la-ansiedad-durante-la-cuarentena

Rodríguez Hernández, J. A., y Santana Bonilla, P. J. (2006). Maestras y maestros: un análisis de la distribución de tareas docentes y domésticas. Revista de Educación, 340, 873-922.

Sánchez, A. (27 de junio del 2020). Home office, nueva normalidad laboral. El Universal. Recuperado de https://www.eluniversal.com.mx/cartera/home-office-nuevanormalidad-laboral-despues-del-coronavirus

Sanchís, S. (2020). La convivencia familiar en tiempos de pandemia. Cómo preservar el autocontrol y manejar el conflicto [mensaje en un blog]. Recuperado de https:// caxtoncollegeschoolblog.caxtoncollege.com/2020/04/06/la-convivencia -familiar-en-tiempos-de-pandemia-como-preservar-el-autocontrol-y-manejar -el-conflicto-family-life-in-times-of-pandemic-how-to-preserve-self-controland-manage-conflict/ 
Secretaría de Salud. (2020). COVID-19 México. Información general. Dirección General de Epidemiología. Recuperado de https://coronavirus.gob.mx/datos/

Sierra, J., Ortega, V., y Zubeidat, I. (2003). Ansiedad, angustia y estrés: tres conceptos a diferenciar. Revista Mal-estar e Subjetividade, 3(1), 10-59.

Suárez, V., Suárez Quezada, M., Oros Ruiz, S., y Ronquillo de Jesús, E. (2020). Epidemiología de COVID-19 en México: del 27 de febrero al 30 de abril de 2020. Revista Clínica Española, 220(8), 463-471. https://doi.org/10.1016/j.rce.2020.05.007

UNESCO, ONU Mujeres y Plan Internacional. (2020). Género, educación y COVID-19. ¿Consecuencias para niñas y adolescentes? Recuperado de https://es.unesco.org/sites/ default/files/plan-internacional-onumujeres-genero-educacion-covid-19.pdf

Universidad Autónoma Metropolitana (UAM) (productor). (2020). Conversatorio "Salud mental y docencia remota" [archivo de video]. Recuperado de https://www. youtube.com/watch?v=iX0093yA-qo

UAM Iztapalapa Oficial (productor). (2020). Conversatorio: "Experiencias de docentes, alumnas y alumnos UAMI en PEER" [archivo de video]. Recuperado de https:// www.youtube.com/watch? $v=\_z 6 l F Q D b U J g \& t=2285 \mathrm{~s}$

Valadez, B. (21 de abril del 2020). ¿Qué es el síndrome de la cuarentena ante COVID-19? Milenio. Recuperado de https://www.milenio.com/ciencia-y-salud/sindromede-cuarentena-por-covid-19-que-es-y-cuales-son-los-sintomas

Vega Baeza, M. R., y Durán Medina, J. F. (2013). El ciberespacio y la educación: ¿una pedagogía de la rentabilidad? Debilidades y fortalezas. Estudios sobre el Mensaje Periodístico, 19, 1077-1084. 